\title{
Multilevel Security System for ATM Machines
}

\author{
Gudisa Jabili, A.Shilpa Bhatt, Tarun Kosuri, Bharath Pisay, Archana S Nadhan
}

\begin{abstract}
Cash machines and bank cards are currently being used with the ultimate purpose of currency trades and agree a crucial operation in exchange. For eg, the shortcomings of the current validation scheme, the secret key and the Security code triggered a leakage of data put away in ATM payment card that resulted in the loss in cash in ledger and personal data misuse. In order to overcome this vulnerability of theft during cash transactions, it intend to use customers ' fingerprints as a hidden term included with once hidden expression. The consumer will have the right to carry on for exchange after accepted confirmation. Every individual's distinctive biometric label is one of its kind and unchangeable
\end{abstract}

Keywords: Internet of things, Sensors, Driver circuit, Audrino Nano, Microcontroller, DC motors, Biometric, Authentication, fingerprint

\section{INTRODUCTION}

Today figures are increasing for the ATM clients. The ATM system is fitted with magnetic strip as well as controls for accessing gadgets and show, container with currency, transaction scanner, machine output voice. Cash machines bind to a CPU with numbers. This is a growing portal where different ATM systems evolve to be customers must have. This server machine has belonged to numerous businesses, neutral carrier firms. Pin owners of ATM cards are exclusive to one another. The selection confirms through the financial institution which helps clients can access their portfolio. Its credential is the most efficient authentication such that when they have the token and correct keys, all of us can have the right of access to the database. If the wallet and key were compromised by the attacker they will steal additional money from the account in the fastest period, which will cause massive cash loses to the consumers. Biometric generation is the highest biometric process that is considerably common and developed, and is the very first-class to be implemented and with a stronger protection credential. This is simple to use and an fingerprint recognition device often takes minimal work and time to collect one's fingerprint. a Therefore, the

Revised Manuscript Received on April 02, 2020.

* Correspondence Author

Gudisa Jabili*, Dept. of CSE, GITAM Deemed to be University, Bengaluru, India. Email: jabili410@gmail.com

A.Shilpa Bhatt, Dept. of CSE, GITAM Deemed to be University, Bengaluru, India. Email: shilpabhatt657@gmail.com

Tarun Kosuri, Dept. of CSE, GITAM Deemed to be University, Bengaluru, India. Email: tarunkosuri8@gmail.com

Bharath Pisay, Dept. of CSE, GITAM Deemed to be University, Bengaluru, India. Email: pisaybharath88@gmail.com

Mrs.Archana S Nadhan, Asst professor, Dept. of CSE, GITAM Deemed to be University, Bengaluru, India. Email: archana.snathan@gitam.edu

(C) The Authors. Published by Blue Eyes Intelligence Engineering and Sciences Publication (BEIESP). This is an open access article under the CC BY-NC-ND license (http://creativecommons.org/licenses/by-nc-nd/4.0/) identification of fingerprints is considered as the lowest demanding of all techniques for fingerprint recognition. While fingerprints will begin with collected pictures, the photographs are not preserved somewhere inside the server. Instead, the fingerprints are transformed into prototypes where the real fingerprints will not be replicated; thus, it is not necessary to abuse the tool

\section{LITERATURE SURVEY}

We may get cash from ATM machines every time the best. We would need fingerprint verification to just do the safe transactions. Fingerprint identification is a relatively new field which can be discussed. Fingerprint regulations and guidelines are being evaluated now in electronics and fingerprinting business practices. There are three prominent assaults against ATM, as said by Madhusudhan reddy and Krishna murthy: Glancing, Button logging, and loss of credibility. Opposite of handheld devices, there are also assaults: set up bogus cell applications, key logging tools, and catch the range of PINs at any stage of transmission. In fact, an attack may also be a sum of each form of such assaults. Data might be accessed via a network attack of elements [2]. This is observed where hackers seek to access login details of the client who saved on the rear side of the ATM card at the barcode gift. Key might be the only Key that may be used to validate Debit card proprietors. This method any person will get access to the deposit account by ATM device since the key inserted is right. Then, if the Debit card and key have been lost or robbed by almost anyone, they will comfortably transfer funds from a certain bank without the difficulty of input validation. Customer verification is important as it ends in a breach of the confidentiality of knowledge about financial institution account. This problem appears to be worse since anyone can view the information stored after entering the right key to get view to ATM card on ATM system. Financiers gather fingerprints and phone numbers of customers in their computer at the same time as starting money due, and then the handiest consumer gets access to the ATM network. The function of the ATM device seems to be that whenever a patron area has a thumb on the thumbprint device, it produces robotically distinctive four-digit code as a text to the designated customer's cell via Wireless module connected to the microprocessor every time. The code obtained through the customer is inserted into the ATM gadget with the assistance of the key on the touch panel as a matter of urgence. Upon joining it determines whether or not it is a legitimate miles or not and requires the customer to obtain further access.Most finger scanning technology is focused mainly on trivialities. It is claimed about 88 percent for fingers scanning technology is centered on matching minutiae so that matching patterns is the biggest advantage. 
This technique focuses the feature isolation and prototype creation on a sequence of grooves, rather than individual points. The usage of several ridges eliminates reliance on technicalities points, which appear to be tormented by depreciation. The drawback to sample synchronization because at any stage in the testing it is extra touchy to position the thumb and the prototype produced is many times spaced. Thumb-experiment equipment is being evaluated and is capable of unacceptable precision rates. Fingerprint identification, definition and analysis have a long history. This has set the thumb-scan away from other fingerprint technologies along with the distinct features of the fingerprints. There are more unique anatomical features than fingerprints (e.g. iris and retina), but automatic recognition systems capable of exploiting these features has been the most useful developed in recent years. The technology has gotten simpler, more efficient and with a number of ways to offer. The machines are marginally thicker than a penny and one inch rectangular in length and system pics. And ambient link-of-sale. Fingerprint data are distinct from financial records, so impressive

\section{EXISTING SYSTEM}

In today's financial atmosphere, it bodes well for use cash on ATM efforts to establish safety that doesn't address genuine business dangers. There are numerous routes for robbery, ATM, for example, skimming and card burglary will be shown. These days, utilizing the ATM which gives clients the helpful banknote exchanging is extremely basic. On the other hand, the money related wrongdoing course climbs over and again lately; a ton of culprits' messes around with the ATM terminal and take a client's charge card and watchword by illicit means. When the consumer's debit card is misplaced and the key term is robbed, the thief can collect all the money for the briefest moment, giving the consumer enormous financial misfortunes.

\section{PROPOSED SYSTEM}

The idea is to use biometrics as passwords at the hand of OTP in ATMs. The use of fingerprints would reassure consumers by preventing unauthorized access to account and maintaining protection. A Verification module here and a GSM module is used wherein GSM module generates a One Time Password that is required to type on the display and Fingerprint module deals with the fingerprint authentication manner.

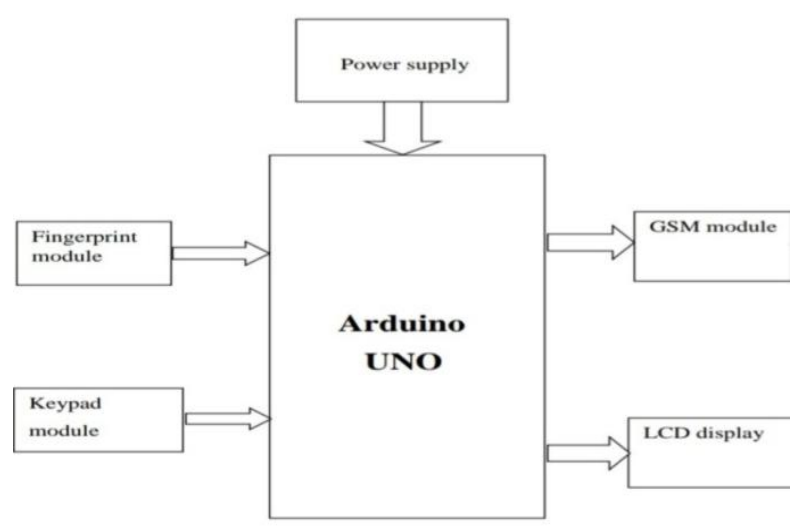

Fig 1: Architecture of Proposed System

\section{V.METHODOLOGY}

Following are the components we use here.

1.Arduino Uno

2.Fingerprint module

3.GSM module

4.Keypad

5.LCD display

An integrated computer is a mixture of operating systems for performing a dedicated task. Integrated circuits and signal processing are two of the key instruments used in integrated products. A fingerprint based totally definitely ATM money box having access to device the use of microcontroller is applied. Initially we hold an individual's fingerprint and to be proved with the fingerprint we send during validation period. When both finger prints are compatible therefore the ATM money box will unlock. The instructions connected with the task will be packed into the configured circuit board and use the Integrated $\mathrm{C}$ syntax. The package includes a microcontroller panel, a verification device and a function generator which collects biometric data from the module. Because it is entirely focused on thumb verification, there is no chance of passwords or pins being exposed.

The fundamental motivation for using biometric generation is to efficiently and correctly control get entry to with the aid of authenticating users thru their specific biometric characteristics such as fingerprint approach. Fingerprint scanning, maintains to benefit acceptance as a reliable shape of securing access thru identity and verification processes.

It is vital that to first understand the fundamental of a biometric primarily based security gadget. The utilization of the ATM security framework through utilizing biometric structures it's far a paramount gadget and extraordinarily difficult and tough. This system is distinctly important to manipulate crook statistics.

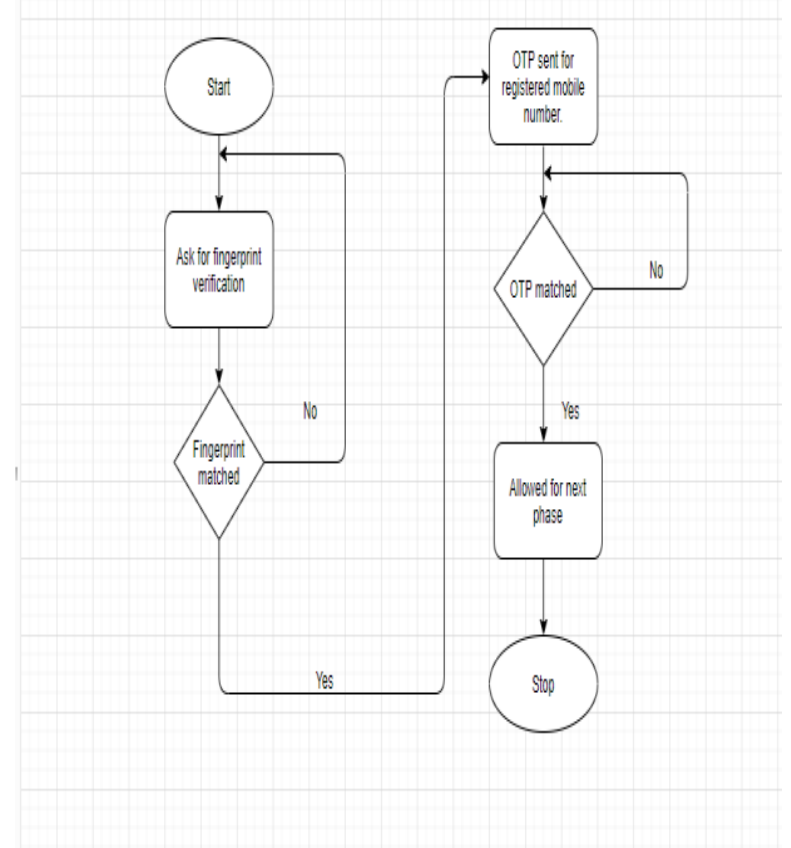

Fig 2: Flow chart depicting dataflow 


\section{RESULTS}

The results that will be displayed are :

1)Asks for the live fingerprint to check with the stored ones.

2)Sends OTP to registered mobile number.

3)OTP should be typed and it must match.

\section{CONCLUSION}

The conclusion of this undertaking is that the cardboard should be replaced and it need to be easy, easier, dependable, and cozy. Biometrics is a way of verifying non-public identity by means of measuring and studying precise bodily or behavioural characteristics of man or women like fingerprints. The cause of this mission may be to have a look at the use of biometrics era and OTP technique to determine how secure it might be in authenticating person's and how the users job characteristic or position would effect the authentication method or protocol. The fingerprints machine is generally endorsed to be completed because of the fact it is a good deal much less complex, dependable, possible, at ease and without problem felony to each person. And there's no any fear that anyone can steal my fingerprint. In fingerprint payment gadget patron has to vicinity his fingers at the finger scanner and then scanner will recognize the account which belongs to that man or woman and the individual must input the quantity that is despatched to their cellular wide variety after which fee the invoice. So it is straightforward for the user because of its reliability

\section{REFERENCES}

1. American Journal of Engineering Research (AJER) e-ISSN: 2320-0847, p-ISSN : 2320-ume-6, Issue-8, pp-41-45. www.ajer.org

2. Nor Fazlina Mohd Amin, Shorayha A/P Eh Chong, Nur Zafirah Abd Hashim, Hassan Chizari, Security Issues in ATM Smart Card, Technology, International Journal of Mathematics and Computational Science, Vol. 1, No. 4, 2015, pp. 199-205, http://www.aiscience.org/journal/ijmcs

3. Samir Nanavati, Michael Thieme, and Raj Nanavati, "Biometrics: Identity Verification in a Networked World", John Wiley \& Sons, 2002.

4. Julian Ashbourn, "Biometrics: Advanced Identity Verification", Springer-Verlag, London,2002.

5. A Study of Possible biometric solution to Curb Frauds in ATM Transaction, IJASCSE

Theme based issue 3,2013.

\section{AUTHORS PROFILE}

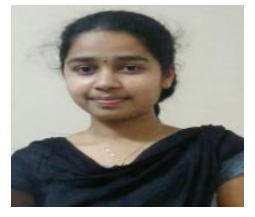

Gudisa Jabili pursuing final year B.Tech at GITAM Deemed to be University, Bengaluru. Her areas of interest are Data Analytics and Machine Learning. She has certifications on Big Data Analytics and Robotic Process Automation. She has done projects on Smart bin and generation of Student report using RPA.She completed her schooling at Gurukul vidyapeeth techno school and higher education at Sri Chaitanya Educational Institution.

Email-ID-jabili410@gmail.com

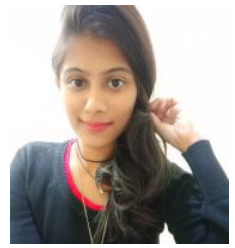

A.Shilpa Bhatt pursuing B. Tech Final Year at GITAM, Bengaluru. Her areas of interest are computer networks and web technology.She has done projects on Automated street Light Systems.She completed her schooling at Montessori High school and higher education at Sri Chaitanya Educational Institution.

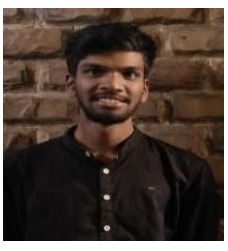

Tarun Kosuri B.Tech Final Year at GITAM, Bengaluru. He has been certified in Big Data by Dell Emc. His areas of interest are Internet of Things and Web Technologies. The projects he completed are Certification Generation using Robotic Process Automation. He completed his schooling at Vikas the concept school and his secondary education at Sri Chaitanya Junior College.

Email-ID-tarunkosuri8@gmail.com

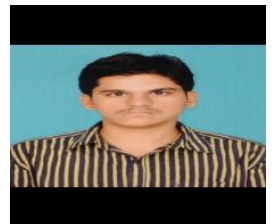

Bharath Pisay pursuing B.Tech final year a GITAM, Bengaluru. He areas of interests are IO and cyber security. He has done various projects which includes network security in national informatics centre . He completed his schooling at Sri Chaitanya School and completed his higher education at Narayana Junior College.

Email-ID-pisaybharath88@gmail.com

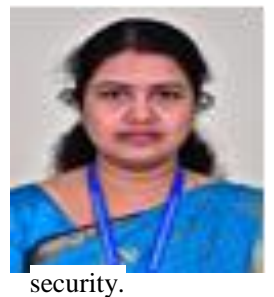

Mrs.Archana S Nadhan is an assistant professor in the department of computer science and engineering, School of Technology, GITAM Deemed to be University, Bengaluru Campus. She has 13 years of teaching experience and currently she is pursuing $\mathrm{PhD}$. in IoT security in GITAM deemed to be University from 2017. Her areas of interest include Computer networks, IoT and cyber

Email-ID-archana.snathan@gitam.edu

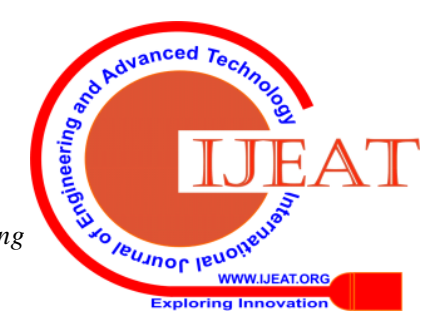

